\title{
Singularidades no processo de escrita de sujeitos em estruturação psicótica
}

\author{
Fátima Lucília Vidal Rodrigues \\ Universidade de Brasília \\ Margareth Schaeffer \\ Universidade Federal do Rio Grande
}

\section{Resumo}

Este artigo tem como objetivo apresentar singularidades no processo de escrita de sujeitos em estruturação psicótica, percebidas a partir das interrogações construídas na observação, acompanhamento e análise das produções escritas de sujeitos que participaram de pesquisa acadêmica coordenada pelas autoras. 0 texto apresenta questões e, a partir de uma abordagem ética inclusiva e psicanalítica, traz as produções escritas nos trabalhos dos sujeitos acompanhados, as quais são teoricamente categorizadas; Jacques Lacan é um dos principais autores que alicerçam a análise teórica.

Palavras-chave: Escrita. Psicose. Educação inclusiva. 


\section{Particularities in the process of writing in subjects with a psychotic structure}

This article aims to present some peculiarities of the writing process in subjects with a psychotic structure, perceived through questions based on observation, monitoring and analysis of the written productions of individuals who participated in the academic research coordinated by the authors. The paper presents some issues and, based on an inclusive, ethical and psychoanalytic approach, brings forth the theoretically categorized written productions in the works of the individuals monitored. One of the main authors underpinning the theoretical analysis is Jacques Lacan.

Keywords: : Writing. Psychosis. Inclusive Education.

\section{Singularidades en el proceso de escritura de los sujetos en estructuración psicótica}

Este artículo tiene como objetivo presentar algunas peculiaridades en el proceso de escritura de los sujetos en estructuración psicótica, compiladas a partir de las preguntas basadas en la observación, seguimiento y análisis de las producciones escritas de los individuos en la investigación académica coordinada por los autores. El documento presenta algunas cuestiones y, desde una ética inclusiva y psicoanalítica, trae producciones teóricamente clasificadas y ejemplificadas con el trabajo de los individuos acompañados. Jacques Lacan es uno de los principales autores que sustentan el análisis teórico.

Palabras clave: Escritura. La psicosis. La educación inclusiva. 


\section{Introdução}

Conto ao senhor é o que eu sei e o senhor não sabe; mas principal quero contar é o que eu não sei se sei, e que pode ser que o senhor saiba (Riobaldo in Grande Sertão: Veredas, de João Guimarães Rosa).

A importância de efetivarmos uma prática pedagógica consciente e ética na direção do sujeito justifica a escrita desse artigo, pois a combinação de uma ética inclusiva que pressupõe uma sociedade mais solidária - com uma ética psicanalítica - que reconhece o sujeito e seu desejo - pode modificar as instituições que se ocupam de formar novos cidadãos, mais transformadores, criativos e solidários. A escola é uma instituição que deveria se adaptar aos educandos, conforme esses fossem modificando a instituição. Infelizmente, o que vemos é uma grande dificuldade em trabalhar com a diferença e a diversidade. A escolha em trabalhar com sujeitos que têm feito marca na escola foi deliberada e calcada no desafio de pensar uma temática que ainda não foi, exaustivamente, tratada a partir do olhar dos professores. A combinação de uma ética inclusiva e psicanalítica pode construir oportunidade para um fazer educacional mais criativo aos alunos em processo de inclusão, com especial destaque para os alunos com transtornos globais do desenvolvimento. Apresentamos a seguir as questões que nos mobilizaram a investigar sobre a temática da escrita e da estruturação psicótica.

Autores como Lacan, Certeau, Derrida, Jakobson, Saussure, Bhabha ajudaram-nos a construir a seguinte questão: Como se constituem as singularidades na produção escrita de sujeitos em estruturação psicótica, as quais devemos considerar, quando pensamos a intervenção pedagógica? A partir dela, fomos percebendo a importância da apropriação de uma ética psicanalítica pela educação, ou seja, do reconhecimento do sujeito e do outro na constituição e na construção de saberes pedagógicos. Nosso objetivo, então, passou a ser: investigar e problematizar como se constituem as singularidades no processo de escrita dos sujeitos em estruturação psicótica, a partir do material empírico e à luz das teorias. Decorrem desse objetivo alguns desdobramentos importantes, os quais pretendem responder às questões norteadoras, que delimitam outros objetivos mais específicos: descrever singularidades existentes no processo de produção de escrita dos sujeitos em estruturação psicótica, e problematizar e circunscrever algumas intervenções pedagógicas que descrevam as singularidades do processo de escrita dos sujeitos acompanhados.

Pensando os sujeitos dessa pesquisa, nossa hipótese principal de trabalho é que há singularidades as quais devemos considerar na intervenção pedagógica e que, dependendo da lente que usamos para olhar os sujeitos em estruturação psicótica, encontra- 
mos, ou não, singularidades pertinentes a uma intervenção pedagógica comprometida com este saber-fazer tão singular. Logo, supomos que a partir da psicanálise podemos descrever como essas singularidades se constituem. Supomos ainda que o desenvolvimento desse trabalho sirva para apontar questões, mesmo que iniciais, e ajudar-nos a qualificar nossa prática pedagógica.

\section{Interlocuções entre o campo teórico e o campo empírico}

Optar pela psicanálise significa optar por uma ética psicanalítica que reconhece o sujeito do desejo. A combinação de ética, experiência e desejo é a marca lacaniana de uma abordagem que não prescinde do sujeito em sua articulação com a criação e a existência. Ser professor e viver a docência a partir dessa abordagem pode nos dar condições ímpares de ver e mediar os processos de conhecimento de nossos alunos e alunas.

Por que o recorte da psicanálise, especialmente da psicanálise lacaniana? São inúmeras as teorias que podem dar suporte às diferentes práticas educacionais que vemos na escola. Jacques Lacan não teve nenhum interesse em discutir as questões escolares, mas teve muito interesse em problematizar e construir uma teoria que explicasse, a partir do seu campo teórico e ético, a constituição do sujeito. Quando consideramos a especificidade dos sujeitos acompanhados e percebemos o rigor necessário ao trato com as produções dos sujeitos apresentadas (Mateus, Marcos e Lucas), mesmo reconhecendo a existência de várias outras abordagens não menos comprometidas com os sujeitos optamos pela abordagem que prioriza o sujeito na linguagem. Uma teoria que vislumbra a possibilidade de ser na linguagem (Schäffer, 1999) e que nos dá elementos para criar uma intervenção pedagógica responsável e comprometida com o outro e com o social.

0 conceito de psicose perpassa toda a obra de Lacan e é discutido particularmente em três obras: em sua tese de doutorado com o caso de Marguerite Anzieu; no Seminário III, As psicoses, com o caso Schreber, e no seminário vinte e três, com o caso James Joyce. 0 autor elabora a si mesmo nesse movimento, que não tem características cartesianas e sim de desconstrução e construção do já dito.

Para Lacan (1998), a psicose é tomada como um fracasso na constituição do sujeito na sua relação com a ordem simbólica. Seu avanço teórico é visível quando implementa, por um lado, as categorias do Real (R), Simbólico(S) e Imaginário (I) e, por outro, a teoria da lógica do significante. No início de suas escritas ele insere a questão da loucura no campo da fala e da linguagem e reafirma que o mundo das palavras cria o mundo das coisas, introduzindo a questão da nomeação. No Seminário III, Lacan (1988a) 
afirmou que uma das condições para o diagnóstico da psicose são os distúrbios na ordem da linguagem, mas, cuidadosamente, alertou: "para que estejamos na psicose, é preciso haver distúrbios de linguagem, e é essa, em todo caso, a convenção que thes proponho adotar provisoriamente" (Lacan, 1988a, p. 110). 0 delírio talvez tenha sido o mais importante desses distúrbios. Lacan (1988a, p.141) diz que "a análise do delírio nos revela a relação fundamental do sujeito no registro no qual se organizam e se desenvolvem todas as manifestações do inconsciente".

Sabemos que um dos textos em que este autor trabalhou e apresentou sua elaboração mais conhecida sobre a psicose foi o texto De uma questão preliminar a todo tratamento possível da psicose, incluído em sua obra Escritos (1998). Nele, aparece a mais conhecida afirmativa lacaniana: "o princípio é a foraclusão (Verwerfung) do Nomedo-Pai" (Lacan, 1998, p. 584), a qual representa uma conclusão de Lacan numa determinada época e contexto. Sem dúvida, o conceito de que a psicose é a foraclusão do significante do Nome-do-Pai foi e ainda é uma de suas teses mais significativas acerca das psicoses. A construção do conceito de Letra por Lacan (1998) inicia-se no seminário sobre a Carta Roubada. Nele, a letra/litter é tomada como fonema ou como carta/letter. Nesse seminário, o autor trabalha um conto de Edgar Allan Poe, e o deslocamento de letra (materialidade) para carta (transmissão de mensagem) ocorre ao longo do texto. 0 grande desafio para os sujeitos da pesquisa em questão é escrever para além de uma materialidade. 0 que percebemos na intervenção escolar é que, após um tratamento pedagógico, os alunos escrevem codificadamente, ou seja, uma escrita mecânica que responde a uma demanda específica do professor. Escrever transmitindo uma mensagem ou iniciar uma tentativa de fugir da relação objetal com a letra é muito difícil se o que deve ser escrito já está dado. Quando se permite uma escrita espontânea, algo do sujeito aparece e ele consegue transmitir. Nos Escritos, Lacan (1998, p. 498) diz que devemos tomar a letra ao pé da letra, e ele a designa como "suporte material que o discurso concreto toma emprestado da linguagem". Se ela é o que insiste do inconsciente, acredito que temos um longo caminho teórico a percorrer, juntamente com os dados empíricos.

O conceito de letra nas últimas obras de Lacan (1985) aparece como algo manejável, algo que pode ser rasurado ou eliminado. A letra é transmissível e pode representar o sujeito para outro significante, como se fora um significante, mas não o é. 0 significante é indestrutível, passa de S1, para S2, para S3... 0 significante representa o sujeito para outro significante. Os diferentes aspectos levantados em torno da letra são, a meu ver, o próprio movimento de suplementariedade encontrada nas obras de Lacan. Se antes era - seminário A Identificação e o seminário A Carta Roubada - letra como fonema, como texto escrito, reduzida ao traço (la trace/le trait), agora - seminário Mais, ainda e 
seminário De um discurso que não seria o do semblante - ela difere de si mesma, é litoral (entre saber e gozo), é limite, é matema, ou seja, capaz de se transmitir integralmente (Rodrigues, 2003, p. 78, grifos da autora).

Se a Letra pode representar o sujeito para outro significante, ela também pode unir o que está solto e dar lugar ao sujeito. Em Outros Escritos (2003), Lacan aponta para essa marca litoral que faz borda e assim possibilita limite, fazendo furo no saber e borda no objeto, sem se ensimesmar com ele.

Os sujeitos dessa pesquisa conseguem, porque estão na linguagem - mesmo estando fora do discurso, como afirma Soler (2007) -, construir algumas pontes para estar no discurso. 0 outro, para quem suas escritas são endereçadas, pode significar as pedras dessas pontes com pontuações que permitem e autorizam uma espécie de publicização do seu discurso. Há palavras que funcionam como nome próprio em suas escritas, e essas podem e devem ser escutadas e reconhecidas como uma forma singular de entrar na cultura escrita e na cultura letrada da escola.

“A noção de letra se introduz com todos esses aspectos de cortar, de rasurar, de apagar, porque, nesse meio de identificação, esse sentido é absolutamente preciso. É próprio da letra ser diferente não só de tudo que a rodeia [...]" (Ritvo, 2000, p. 13). A questão da letra é uma questão de privação na origem: a primeira é sempre a segunda. Nunca vamos encontrar a primeira vez em que ela foi dita. A letra vai ter um vínculo com o Real, vai, de fato, ser a própria noção do impossível. No Seminário XVIII, Lacan irá dizer que a Letra e a escrita são no Real, ou seja, representam a impossibilidade de ser todo, e o significante é no simbólico. 0 que se passa com os sujeitos desta tese é que ser marcado como não-todo é o que não ocorre, pois na psicose há uma falta de corte, limite, e o que vemos em Lacan é que a Letra (esse quarto) é o próprio limite. Trabalhamos com os sujeitos e percebemos que a letra (o código) está lá e pode ser utilizada das mais variadas formas. 0 desafio é transformar esse escrever em algo que faça sentido e dê condições de mudar o seu estatuto. A escrita pode funcionar como um laço articulador na linguagem. Ela é o que amplia para além aquilo que resulta da linguagem. Como defende Lacan (1985, p. 61), “recusar-se à referência à escrita é proibir-se aquilo que, de todos os efeitos da linguagem, pode chegar a se articular. Essa articulação se faz naquilo que resulta da linguagem o que quer que façamos, isto é, um suposto aquém, e um além".

As escritas dos sujeitos em estruturação psicótica têm um efeito estruturante em si mesmas para eles, e por isso o processo de escrever pode garantir a abertura de um espaço intervalar, no qual o outro o auxilia a sustentar sua existência. A escrita pode proporcionar um deslizamento/alargamento, desde que haja um outro apontando 
para ela. Nos três casos acompanhados, percebemos que os empréstimos de sentido e da significação às escritas produzidas somaram-se à possibilidade de enlace com o que estava fora, com o social.

A partir das produções compiladas junto aos três sujeitos que enriquecem este trabalho, foi possível construir algumas hipóteses iniciais acerca de categorias importantes na problematização dos seus processos de escrita, as quais podem ser consideradas no trabalho pedagógico. Essas categorias podem ser divididas em dois blocos, um que acolhe a escrita como produção que viabiliza o sujeito em extensão, ou seja, que o coloca no enfrentamento com o outro e com o social, e outro que o coloca no enfrentamento com as suas limitações, potencialidades e endereçamentos da escrita própria para si.

\section{A escrita endereçada ao outro e ao Outro}

\section{A escrita tem caráter de suplementaridade e não de complementaridade}

Se considerarmos que o que faz elo/nó aos três registros lacanianos - Imaginário, Simbólico e Real - tem característica suplementaria, veremos que a escrita só se suspende com sentido quando ela própria se organiza em torno da suplementaridade que representa na direção do outro. Lacan (2007), no seminário 22, aula cinco, diz que só algo como os Nomes do Pai poderia exercer essa função de suplementaridade no enlace dos três registros, e é por isso que não podemos falar em escrita como complementaridade. Ela não completa o sujeito, ao contrário, ela dá a ver o que falta.

A escrita de Lucas (Figura 1), um dos sujeitos, pode exemplificar sua passagem por sobre as linhas, e tem caráter suplementar, no sentido que dá a ver o que falta e se detém sobre a linha. Suplementa-se, amplia-se sobre o traço. 
Figura 1 - a escrita sobre a linha

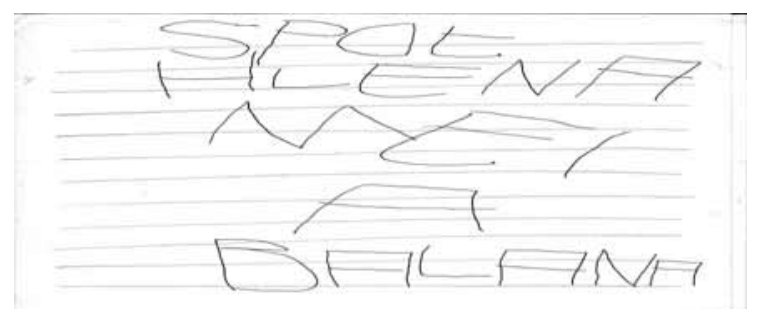

Figura 2 - a escrita na linha

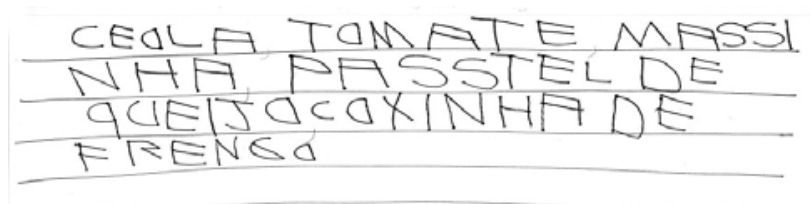

A introdução da barra como limite no papel desafia Lucas a suportar uma espécie de borda de linha orientadora da escrita. Ela suplementa o branco da folha e faz com que Lucas comece a fazer questão dessa marca que chega antes do seu traço na produção. Ele olha, titubeia e, por fim, escreve. Com o passar do tempo, respeita-a e começa a escrever, colocando sua letra nessa entre-linha (Figura 2).

\section{As cartas como possibilidades de endereçamento ao outro/Outro}

Para Lacan (1998, p. 61), “A carta/letra tanto pode surtir seus efeitos internamente, nos atores do conto, inclusive o narrador, quanto do lado de fora: em nós, leitores, e também em seu autor, sem que ninguém jamais tenha tido que se preocupar com o que ela queria dizer: destino comum de tudo que escreve". A leitura do escrito endereçado constitui e poderia ser um recurso utilizado pelas escolas na prática pedagógica com educandos na mesma posição na linguagem que os sujeitos acompanhados para essa pesquisa, sempre que for possível, pois potencializa o outro na escrita e cria condições para registrarmos e darmos publicidade à sua escrita como traço.

Como introduzir elementos que auxiliem o sujeito a armar uma possível separação? Se ele está fora do discurso e não da linguagem (Soler, 2007), como armar laço efetiva- 
mente? Percebemos que a combinação de diferentes espaços terapêuticos, marcados pela psicanálise, pode promover condições para que o sujeito enderece sua escrita ao outro. 0 movimento das cartas é uma possibilidade de leitura do Outro. Com Mateus e Lucas, o movimento das cartas era uma constante. Escrevíamos para personagens, para o psicanalista, para as professoras, e eles respondiam.

Figura 3 - a escrita com destinatário

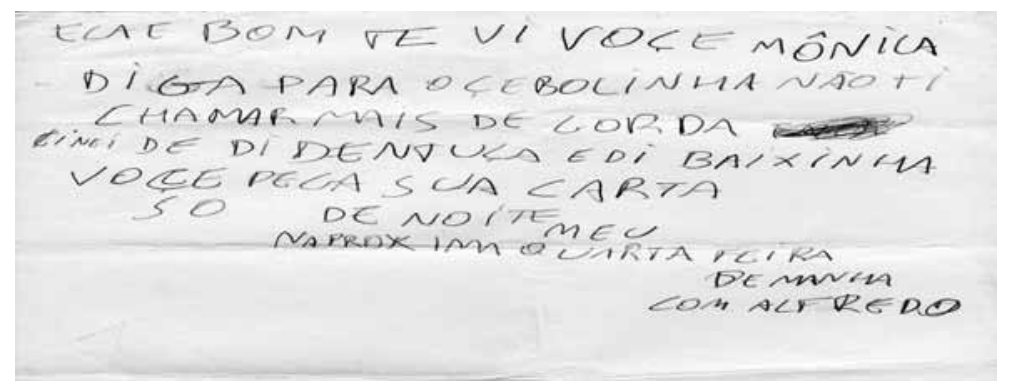

\section{0 que retorna do que se escreve - o efeito de se ouvirem}

Quando trabalhamos com escrita e leitura, inevitavelmente nos remetemos à compreensão do que foi lido na escrita do papel. Um conceito importante e que merece um breve destaque. 0 fato de lermos para os alunos o que eles escrevem faz com que nós marquemos a sua escrita e possibilitemos que eles possam movimentar-se na direção da polissemia do seu significante, ou seja, tentamos, com nossa entonação, com o empréstimo dos sentidos, com a nossa posição de não saber o que está escrito, tirar o caráter de monossentido do significante. 0 que está em jogo é criar uma atmosfera onde seja viável a escuta da sua palavra e, assim, ser nela. A palavra tomada por empréstimo pelo professor pode ser devolvida no só-depois. Então a espera e o silêncio podem ter um efeito de autonomia do sujeito em relação a sua escrita. Ouvir-se no outro e tornar a ser.

Para os três sujeitos dessa pesquisa, o olhar e a voz do outro tinham um lugar especial. Cada vez que se lia ou relia suas escritas, era como se a voz e o olhar fizessem algum tipo de marca no corpo. No início, Mateus balançava o corpo, Marcos ria e Lucas emitia alguns sons guturais. Com o tempo, uma espécie de sustentação pela leitura das suas escritas, mediadas pela voz e o olhar do outro, dava lugar às leituras feitas por eles mesmos. Mateus lia fluentemente e gostava do que ouvia, era como se sua escrita 
ganhasse contornos de novidade, como se estivesse lendo uma história pela primeira vez. Marcos e Lucas reconheciam palavras soltas, e, dessa forma, Lucas, aos poucos, começou a querer ler. Com um gravador digital registramos essas leituras e ouvíamos juntos, assim o reconhecimento de si na leitura da palavra escrita autorizava uma aparecência própria desses sujeitos.

Figura 4 - a escrita como possibilidade de se ouvir

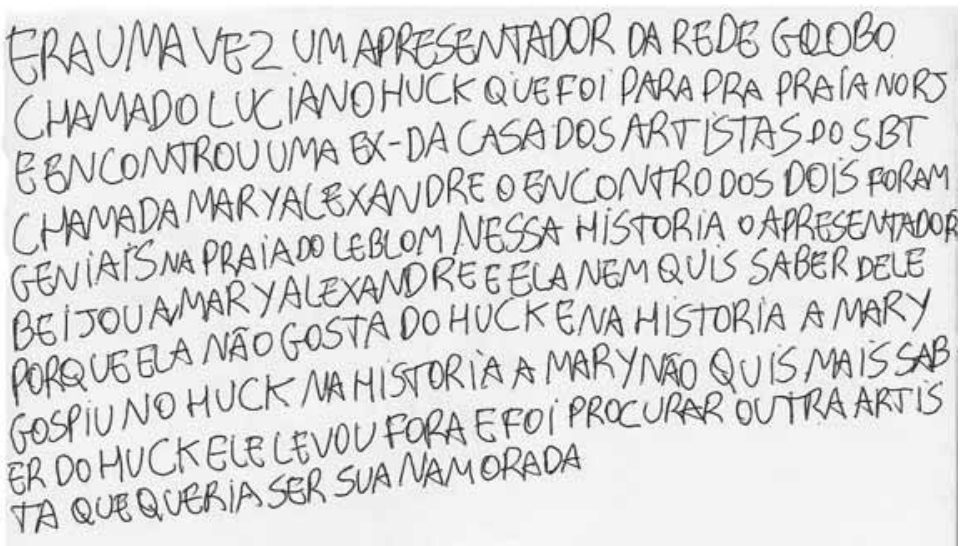

\section{Metáforas, metonímias, holófrases, anáforas e neologismos}

As escritas desses sujeitos são escritas no real, ou seja, eles escrevem literalmente o que veem e o que pensam, numa espécie de escrita automática sem grandes comparações com as escritas dos surrealistas. Falamos aqui do sentido literal e da automação de algumas produções. A metáfora e a metonímia, enquanto comparação e substituição entre as palavras, quase não aparecem, diferentemente do que percebemos com a holófrase, a anáfora e o neologismo. Estes últimos, em algumas produções, são visíveis. A transformação de palavras em palavras-frase e a invenção de novos termos e palavras com sentidos novos aparecem em várias produções. 0 interessante é que quando estudamos essas figuras de linguagem na língua portuguesa vemos que o que dá lugar a um neologismo é a presença da metonímia. No caso dos sujeitos em questão, eles passam direto da palavra no real para uma nova com características de neologismo. 
Figura 5 - as anáforas “eu também fátima”

\section{O F FATIMA}

QUEM ESCREVEUESTACARTA PARA VOCE. FOI O SEU MELHOR AMIGO CHAMADO MATEUS QUEESTA COMMUITAS SAUDADES DE VOCE EA 2 ANOS NÄO TEVE.

FATIMA VOUTE CONTAR ALGUMAS NOVIDADES QUE EU FIZ NESTE ANO DE 2005. EUTIREI O TITULO DE ELEITOR, A CARTEJRA PROFISSIONAL, ACARTEIRA DE TRABALHO, ACARTEIRA DO EXERCITO, A CARTEIRA DE IDENTIDADE EOCPE

EU TAMBEM FA TIMA ME MUOEI PRO JARDIM VILA NOVA QUEE UM LUGAR BOM EM DEZEMBRO DO ANO PASSAOO. EU TAMBEM PAREJ DEVER CANAIS IN FANTIS TAMBEM EM DEZEMBRO DOANO PASSADO. PAREI TAMBEM FATIMA DE COLECIONAR ENCARTES DE LOJA NAS FERIAS DE JULHO DESSE ANO.

EU TAMBEM FATIMA TO GOSTANDOMUITODEMORAR NO TAROIM VILA NOVA PORQVE LA EUME SINTO MELHOR MORANDO NOMEU CONDOMINIO NO TERREO. FATIMA EUESTOU COMMUITAS SAUDADES VOU TE DAR O NOVO NUMERO DA MINHA CASA E TAMBEM DO MEU CELULAR PELA PRI- MEIRA VEZ O NUMERQ DOMEU TELEFONEE 32619505 E DO MEV CELULAR Ë 98794628.

FATIMA EU TAMBEM JA COMECEI A NAMORAR E TAMBEM CONTINUO ESTUDANDONA MESMA ESCOLA ESSE TAMBEM VAI SER MEU ULTIMO ANO NO COLÉGIO PORQUG EU ESTOU NUMA Q3O NA 8: SERIE. EU TAMBEM FATIMA ANDO CANSADO DE ESTUDAR DE MANHA. ANO QUE VEM NO SEGUNDO GRAU FATIMA PENSO EM ESTUDAR DE TAROE POR 3 ANOS EM 2006,2007 E 2008 NOS 3 ANOSESPECIA IS DE EVENTOS ESPORTIVOS QUE SÄO A COPA DOMUNDO AS OLIMPIADAS OS JOGOS PANAMERICANOS EA GURO COPA.

FATIMA UM BEIjO G ABRAÇO

DO SEU MELHOR AMIGO MATEUS

\section{A escrita como potencializadora de si mesmo}

\section{As peculiaridades que envolvem as questões relacionadas com o nome próprio}

Quando o nome próprio começa a aparecer, por escolha do sujeito, algo está se inscrevendo conjuntamente à própria escrita. Vimos que, ao escrever o seu nome, ele busca o reconhecimento do outro, mas no caso de Mateus, Lucas e Marcos percebemos que a escrita do nome ora se coloca como uma simples resposta à demanda do outro e aparece de forma mecânica, ora como efeito de um reconhecimento do outro. Mateus 
escreve diferentes nomes ao assinar suas produções e assim desvia o olhar de quem olha para um outro nome até que, mais tarde, permite escrever o seu nome próprio, escolhido pelos pais e que se configura como palavra única, sua nomeação e perpetuação no mundo. Para Lacan (1998, p. 498), “também o sujeito, se pode parecer servo da linguagem, o é ainda mais de um discurso em cujo movimento universal seu lugar já está inscrito em seu nascimento, nem que seja sob a forma de seu nome próprio". 0 nome parece ser a cristalização da nossa existência pelo discurso do outro. Escrevêlo pode significar uma amarração com o outro, podendo iniciar assim a diminuir a dúvida de estar na vida e, parece, acompanhar-nos.

\section{Figura 6 - o nome próprio}

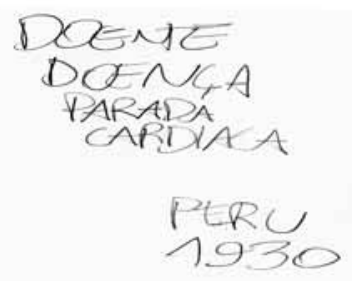

ALFE $D O$

\section{“0 escrever sobre o escrever" - A letra sobre a letra}

A superfície parece ser um dos elementos que faz com que a escrita da letra sobre a letra aconteça. Uma escrita que faz superfície para a letra, sustenta-a e a prende no olhar, um olhar que dificilmente consegue se deslocar do primeiro ponto de foco. 0 olho não corre, está imobilizado com a brancura do papel, e assim permanece mesmo que inúmeras camadas de letras se sobreponham tentando cobri-la.

Às vezes, as escritas das letras sobre as letras de Lucas e Marcos se parecem com breves tentativas de velaturas ["ato de cobrir uma pintura com uma fina e transparente mão de tinta ou verniz, deixando transparecer a tinta da camada anterior" (Houaiss, 2001)]. Uma tentativa inicial de apagamento com marcas. Lacan (1988a, p. 93) comenta que frequentemente há a recorrência à escrita nas psicoses, mas que estas são essencialmente apenas "folhas de papel cobertas com escrita". Eles cobrem o papel tentando encobrir e descobrir as letras. 
Figura 7 - a letra sobre a letra

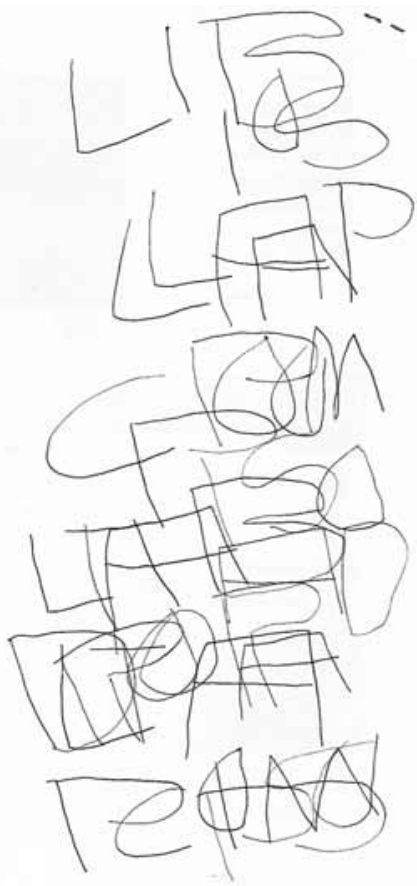

\section{A singularidade da pontuação}

A pontuação pode aparecer como rasuras, espaços em branco e até breves desenhos em meio ao texto. Nossa intervenção pedagógica ajuda muito se for na direção de dar sentido a essa forma singular de pontuar, e assim dar espaço para o uso dos elementos comuns na pontuação. 0 ensino da pontuação na escrita não pode cair na tentação de robotizar, controlar o escrito, mas sim de criar paradas significativas para que o sujeito apareça. Na língua escrita necessitamos tornar o texto e a frase mais claros, e, para isso, a pontuação se configura como um sistema de sinais gráficos que separa unidades significativas.

Com as escritas que vimos é preciso trabalhar a significação para que ponto, vírgula, ponto-e-vírgula, ponto de interrogação, entre outros, ganhem sentido no texto. 0 sentido é trazido sempre pelo ponto final. Por isso, a pontuação ganha um destaque importante nessa discussão, pois é no a posteriori que ela aparece. A psicose poderia prescindir do ponto final? Diríamos que ela é sem o ponto, mas nós podemos emprestá-lo e assim tentar ir além da palavra como coisa ou letra literal e, desse modo, fazer uma marca de pontuação nos textos dos alunos. 


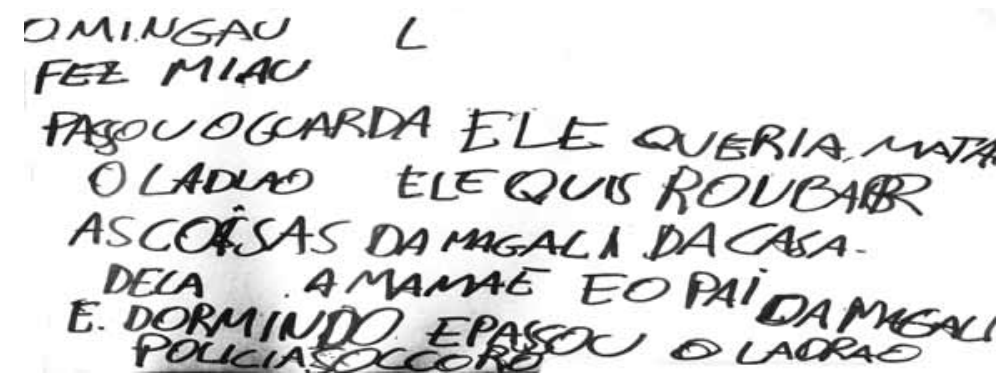

\section{0 uso preferencial da letra caixa alta}

A letra caixa alta, também conhecida como letra de imprensa, é muito usada por esses alunos, e é importante respeitarmos o seu uso. Ela permite certo distanciamento ilusório e uma separação precisa entre as letras. Escrever é sempre uma possibilidade de estar junto e separado. A letra cursiva causa certa indiferenciação do que se escreve, não há espaço entre as letras, e a palavra se destaca pelo puro sentido. Percebemos que muitos alunos preferem fazer a decodificação na hora da leitura, e a letra caixa alta (exemplificada por várias escritas ao longo deste artigo) dá a sensação de que é possível ler "aos pedaços".

\section{0 que se lista quando se lista}

0 desafio com as listas de palavras está em perceber o momento certo de fazer uma intervenção pedagógica. Frequentemente, somos tomados pela angústia de não estar oferecendo as atividades "corretas". Esse é o desafio do professor: poder prescindir do seu planejamento pré-elaborado e dar espaço necessário para que as produções escritas aconteçam. Estas não raro apresentam-se em forma de listas que podem ser psicotizantes, mas também podem servir de ponto de partida para uma organização em direção à própria escrita do sujeito. Ceder e cortar, dois verbos que precisam estar presentes na intervenção com esses alunos. Permitir e direcionar para um sentido, mesmo que emprestado, e daí construir um caminho na direção de um laço necessário com o objeto da escola: a aprendizagem.

As listas são também possibilidade de contagem. Os três sujeitos nessa pesquisa escrevem palavras soltas, mas ao mesmo tempo elas estão ordenadas e organizadas 
a dar contagem, em forma de infinitas listas. Eles as contam para ver se todas estão ali. Mateus escreve os personagens da turma da Mônica e conta seus nomes, Lucas escreve os próprios números da contagem, numa tentativa de se contar entre muitos e de ser diferente. 0 que ele parece intuir é que há algo no campo do Real que não se pode contar, então, ele segue em sua escrita infindável de números.

\section{Figura 9 - as listas}

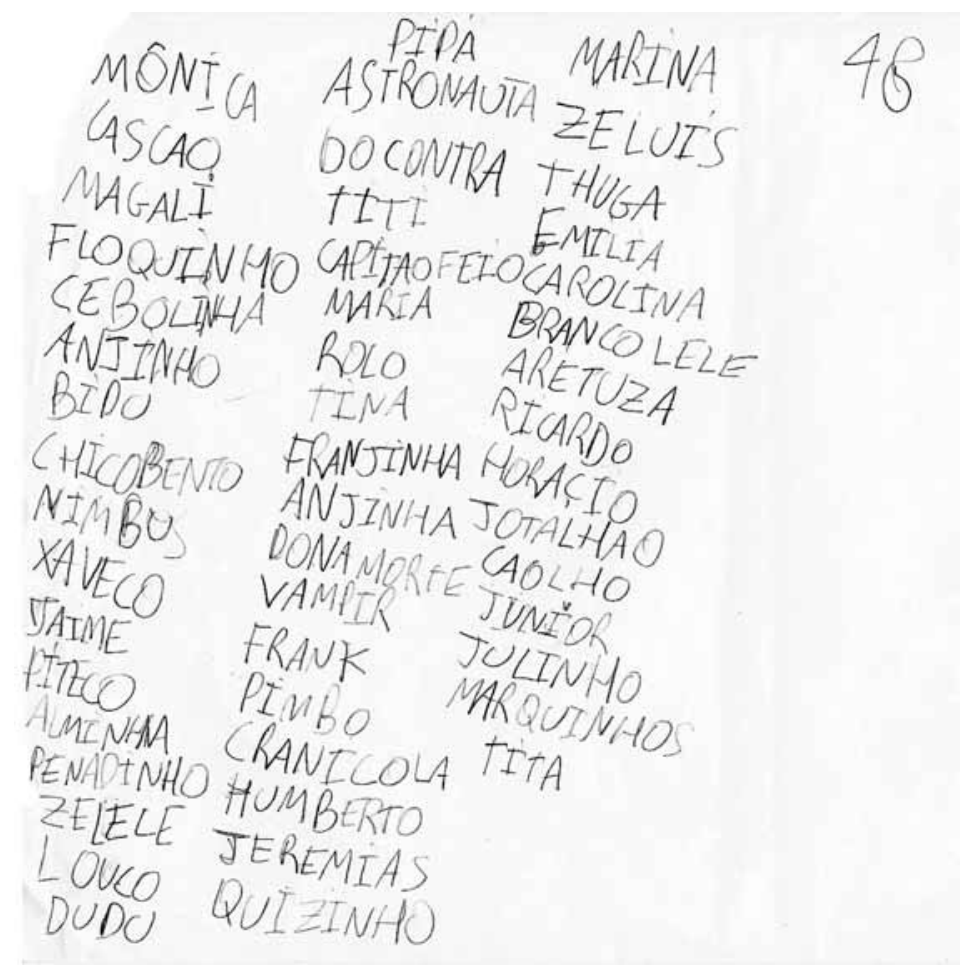

\section{Considerações Finais}

Além de uma intervenção que garanta aos alunos uma escuta para suas idiossincrasias, precisamos não perder de vista os pressupostos de uma Educação para Todos - ACESSIBILIDADE, PERMANÊNCIA E APRENDIZAGEM - e as particularidades da prática com esses alunos - EDUCAR (fazendo com que a noção de espaço de Lei da escola e de socialização se instale), SIGNIFICAR (emprestando sentido às suas singulares construções de linguagem e aprendizagem) e ARMAR ENLACE SOCIAL (marcando, sempre que possível com a palavra, a aproximação do aluno com o sociall. 

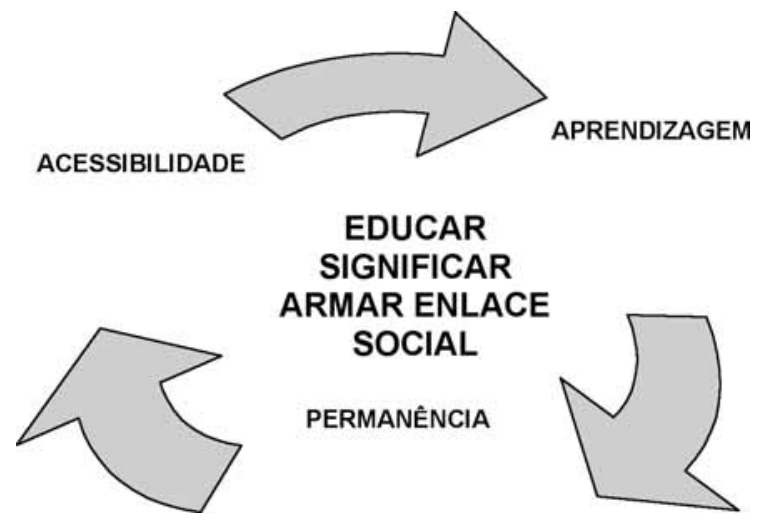

Fonte: Rodrigues et al., 2008, p. 53.

A educação inclusiva, por sua vez, efetiva práticas de acolhimento, permanência e aprendizagem dos alunos com deficiência, transtornos ou altas habilidades, e procura acionar os dispositivos para garantir que todos os alunos aprendam. É uma atuação que tem sua gênese nas políticas públicas e institucionais. Todos se envolvem com um único fim: incluir os alunos e alunas. 0 que temos de fazer agora com o desafio de proporcionar uma educação inclusiva aos sujeitos com uma estruturação psicótica é, como afirma Quinet (2006, p. 49), "substituir a exclusão-reclusão pelo binômio 'foraclusão e inclusão'. E, em vez de foracluir a inclusão, trata-se de incluir a foraclusão". As singularidades na produção escrita de sujeitos em estruturação psicótica, portanto, constituem-se, entre outras possibilidades, em classificações-categoriais, especialmente porque consideramos o espaço intervalar que se coloca entre a escrita da letra como código e como Lei. 0 determinante nessas considerações é o reconhecimento do princípio ético da psicanálise - considerar o sujeito como sujeito da sua própria criação e desejo - como norteador da intervenção pedagógica, o qual possibilita assim ver as produções com outra lente que não seja a exclusiva da pedagogia.

Considerando o trabalho de pesquisa realizado, podemos afirmar que há singularidades na produção escrita de sujeitos em estruturação psicótica que precisam ser consideradas quando pensamos a nossa intervenção pedagógica. Essas singularidades não necessariamente serão encontradas em todos os sujeitos que apresentarem essa condição psíquica, por isso servem de alerta para que não tomemos modelos prontos e fixos de produção de escrita.

De forma qualitativa, ao longo dos últimos anos foi possível identificar que uma intervenção pedagógica pode ser atravessada por uma ética psicanalítica, e assim possibilitar espaço para os sujeitos em estruturação psicótica advirem. 0 contexto atual 
da política educacional brasileira ratifica ações que implementam e implantam a educação inclusiva como proposta reformadora do conceito ético da alteridade, particularmente se pautado por uma ética inclusiva. A experiência vivida junto aos alunos com necessidades educacionais especiais nos faz compreender a urgência de uma prática pedagógica que não colonize os sujeitos, e sim potencialize as novas aprendizagens e saberes.

Uma intervenção pedagógica pautada pelo reconhecimento da fundamental importância de uma inserção no simbólico pelo sujeito, e especialmente pela importância da aprendizagem como movimento estruturante do sujeito, leva-nos a defender que há uma real possibilidade de oferecermos, como professores, condições para que todos os alunos das nossas escolas aprendam. A eles devemos o compromisso profissional com a qualidade da nossa prática pedagógica e com o empenho na permanência e no acesso de todos à escola.

A transferência com esses sujeitos também deve ser salientada, pois "o começo e o fim são sempre a transferência. No início, em potência, proporcionada pelo fato de que o sujeito vem, a transferência está ali, prestes a se constituir. Está ali desde o início" (Lacan, 2005, p. 50). Ela não se estabelece apenas com os sujeitos, mas também com quem está perto, como os familiares e professores. Não passamos imunes por todo esse processo de convivência e pesquisa. Alguns anos foram dedicados ao acompanhamento pedagógico de Mateus, Marcos e Lucas, e as palavras são insuficientes para descrever as mudanças ocorridas em nossos processos de aprendizagem. Somos outros, tomados pela diferença e por nossas escritas.

Podemos concluir que, apesar de esses educandos avançarem muito na interação com o outro e em seus processos educacionais, a partir de uma intervenção pedagógica que garantiu espaço para suas manifestações mais singulares - lembremos que no caso de Mateus, Marcos e Lucas a escrita é o que os mobiliza mais entre os saberes da escola -, pouco avançamos no que diz respeito à separação, que parece sempre impossível. A colagem com o Real de Marcos e Lucas está sempre ali; eles conseguem avançar em muitas aquisições, mas ficam reféns das nossas significações.

Quando Lacan (1998) reconheceu em seu texto De uma questão preliminar a todo tratamento possível da psicose que a psicose está na função e campo da fala e da linguagem, ele nos mostrou que essa desordem do psicótico na linguagem e na fala não é exatamente um caos, mas uma "ordem do sujeito". A exigência de hoje é diferente de anos atrás, e reconhecemos que o processo em questão está para além do escrito, está no experienciado. Para Walter Benjamim (1983), a experiência é algo vivido na intensidade do presente e não algo que só se adquire com o passar do tempo. Todos os envolvidos neste trabalho saem com uma experiência única que desejamos seja envolvida de alteridade com o outro da educação inclusiva. 


\section{Referências}

BENJAMIN, Walter et al. Textos escolhidos. São Paulo: Abril Cultural, 1983. (Coleção Os Pensadores) LACAN, Jacques. Escritos. Rio de Janeiro: Zahar, 1998.

. O seminário. Livro III, as Psicoses. Rio de Janeiro: Zahar, 1988a.

. O seminário. Livro XX, mais ainda. Rio de Janeiro: Zahar, 1985.

. O seminário. Livro XXIII, 0 sinthoma. 1975-1976. Rio de Janeiro: Zahar, 2007.

Nomes-do-pai. Rio de Janeiro: Zahar, 2005.

. Outros escritos. Rio de Janeiro: Jorge Zahar, 2003.

QUINET, Antônio. Psicose e laço social: Esquizofrenia, paranóia e melancolia. Rio de Janeiro: Zahar, 2006.

RITVO, Juan. 0 conceito de letra na obra de Jacques Lacan. Escola Letra Freudiana, v. 17, n. 26. Rio de Janeiro: Contra Capa, 2000.

RODRIGUES, Fátima Lucília Vidal. A produção escrita de sujeitos em estruturação psicótica: para além das letras. 2003. 218 f. Dissertação (Mestrado) - UFRGS, Programa de Pós-graduação em Educação, Porto Alegre, 2003.

Métodos, técnicas e recursos na educação de alunos com síndromes do espectro do autismo. In: KELMAN, Celeste Azulay. Métodos, técnicas e Recursos na educação de pessoas que apresentam necessidades educacionais especiais. Brasília: Editora da UnB, 2008.

SCHÄFFER, Margareth. Subjetividade e enunciação. Educação \& Realidade, Porto Alegre, v. 24, 1999.

SOLER, Colette. $O$ inconsciente a céu aberto da psicose. Rio de Janeiro: Zahar, 2007.

Recebido em fevereiro de 2011.

Aprovado em junho de 2011.

Fátima Lucilia Vidal Rodrigues, doutora em Educação pela Universidade Federal do Rio Grande do Sul. É professora adjunta da Faculdade de Educação da Universidade de Brasília. Atua na área de Educação Inclusiva, aprendizagem, psicose e autismo. Publicação recente: Educação e Função Paterna (Porto Alegre: Editora da UFRGS, 2008) em co-organização com Roselene Gurski. E-mail: vidalrodrigues@yahoo.com.br

Margareth Schäffer, doutora em Educação e professora titular da Universidade Federal do Rio Grande do Sul. Atua principalmente nos seguintes temas: psicanálise, educação, subjetividade, sujeito e linguagem. Publicações recentes: As crianças que não aprendem ensinam? (Educação e Realidade, v. 35, p. 327-332, 2010); Aventura do sentido: psicanálise e lingüística (Porto Alegre: Edipuc, 2002) em co-organização com Leci Borges Barbisan. E-mail: 00009227@ufrgs.br 